\title{
Paronychial Inflammation
}

National Cancer Institute

\section{Source}

National Cancer Institute. Paronychial Inflammation. NCI Thesaurus. Code C112215.

Swelling and redness of the nail folds. 